\title{
Cocaine-Induced Reinstatement Requires Endogenous Stimulation of $\mu$-Opioid Receptors in the Ventral Pallidum
}

\author{
Xing-Chun Tang, Krista McFarland, Stephanie Cagle, and Peter W. Kalivas \\ Department of Neurosciences, Medical University of South Carolina, Charleston, South Carolina 29425
}

The projection from the nucleus accumbens to the ventral pallidum regulates the reinstatement of cocaine seeking in rats extinguished from cocaine self-administration. This projection coexpresses GABA and enkephalin, posing a role for $\mu$-opioid receptors in the ventral pallidum in mediating the reinstatement of cocaine seeking. Rats were extinguished from cocaine self-administration, and the reinstatement of active lever pressing by cocaine was blocked by intra-ventral pallidum administration of the $\mu$ receptor antagonist Cys-Tyr-DTrp-Arg-Thr-Pen-Thr- $\mathrm{NH}_{2}$ (CTAP) $(0.03-3.0 \mu \mathrm{g})$. Conversely, stimulating $\mu$ receptors with morphine $(1-30 \mu \mathrm{g})$ in the ventral pallidum reinstated cocaine seeking. The ability of intra-ventral pallidum morphine to reinstate lever pressing was blocked by co-microinjection of the $\mu$ antagonist CTAP and was augmented by systemic cocaine administration. The reinstatement of cocaine seeking was associated with reduced extracellular GABA in the ventral pallidum, and the reduction in GABA was also prevented by blocking $\mu$ receptors with CTAP $(10 \mu \mathrm{M})$. Although immunoblotting revealed that neither the total tissue concentration nor the membrane insertion of $\mu$ receptors in the ventral pallidum was altered by withdrawal from cocaine, the capacity of morphine (0.01-10 $\mu \mathrm{M})$ to reduce ventral pallidum levels of extracellular GABA was augmented in rats extinguished from cocaine self-administration. These data are consistent with the reinstatement of cocaine seeking being modulated in part by coreleased enkephalin and GABA from the accumbens-ventral pallidal projection, a modulation that may involve the inhibition of GABA release by presynaptic $\mu$ receptors.

Key words: cocaine; ventral pallidum; $\mu$-opioid; self-administration; accumbens; GABA

\section{Introduction}

A cardinal feature of addiction to drugs of abuse is the propensity to relapse after periods of abstinence, and preventing relapse is a promising strategy for treating addicts (Kalivas and Volkow, 2005). The neural circuitry underlying the induction of cocaine craving in addicts and in cocaine-seeking animal models has been partially clarified (Goldstein and Volkow, 2002; Shalev et al., 2002). There is consensus supporting critical involvement of the prefrontal cortex and amygdala glutamatergic projections to the nucleus accumbens in cocaine seeking (Di Ciano and Everitt, 2004; Kalivas and Volkow, 2005). This circuit has been expanded in animal models to include the projection from the accumbens to the ventral pallidum (McBride et al., 1999; McFarland and Kalivas, 2001). Spiny cells in the accumbens projecting to the ventral pallidum are GABAergic and primarily colocalize with enkephalin (Zahm et al., 1985). Enkephalin is a high-affinity ligand for $\mu$-opioid receptors (Waldhoer et al., 2004), and involvement of both GABA and $\mu$ receptor stimulation in the ventral pallidum has been demonstrated in the reinforcing properties of $\mu$ agonist drugs of abuse, such as heroin

\footnotetext{
Received Nov. 10, 2004; revised March 28, 2005; accepted March 29, 2005.

This research was supported in part by United States Public Health Service Grants DA03906, DA12513, and DA05369. We thank Dr. Xuyang Zhang (Department of Biometry and Epidemiology, Medical University of South Carolina) for assistance in conducting the statistical analysis.

Correspondence should be addressed to Dr. Peter Kalivas, Department of Neurosciences, Medical University of South Carolina, 173 Ashley Avenue, BSB403, Charleston, SC 29425. E-mail: kalivasp@musc.edu.

DOI:10.1523/JNEUROSCI.0685-05.2005

Copyright $\odot 2005$ Society for Neuroscience $\quad$ 0270-6474/05/254512-09\$15.00/0
}

(Johnson et al., 1993; Olive and Maidment, 1998; McBride et al., 1999; Xi and Stein, 2000; Caille and Parsons, 2004). Lesion and microinjection studies reveal that the ventral pallidum is also critical for cocaine reward and reinforcement (Hubner and Koob, 1990; Gong et al., 1996), and blocking $\mu$ receptors in the ventral pallidum prevents the acquisition of cocaine-induced conditioned place preference (Skoubis and Maidment, 2003). Thus, the literature supports an important role for $\mu$ receptors in the ventral pallidum in the capacity of either opiates or psychostimulants to reinforce behavior. However, it is unknown whether $\mu$ receptors in the ventral pallidum also regulate the reinstatement of drug seeking.

In addition to behavioral studies, there is neurochemical evidence that opioid and psychostimulant drugs of abuse regulate the GABA-enkephalin projection from the accumbens to ventral pallidum. For example, repeated heroin administration reduces extracellular GABA and elevates extracellular enkephalin in the ventral pallidum (Olive and Maidment, 1998; Caille and Parsons, 2004). Similarly, acute systemic amphetamine administration reduces extracellular GABA in the ventral pallidum (Bourdelais and Kalivas, 1990). Given GABA and enkephalin colocalization, it is possible that the relative changes in the extracellular enkephalin and GABA by drugs of abuse may be causally linked. Supporting this possibility, presynaptic $\mu$ receptors are located on GABAergic pallidal afferents from the accumbens (Olive et al., 1997), and the stimulation of pallidal $\mu$ receptors reduces evoked and basal extracellular levels of GABA (Kalivas et al., 2001; Schroeder and Schneider, 2002). 
The goal of the present study was to determine whether the stimulation of $\mu$-opioid receptors in the ventral pallidum is necessary for cocaine-induced reinstatement of drug seeking in rats extinguished from cocaine self-administration. Moreover, microdialysis was used to determine whether cocaine-induced reinstatement is associated with altered extracellular GABA in the ventral pallidum and whether extracellular GABA is regulated by $\mu$ receptors.

\section{Materials and Methods}

Subjects. All procedures were in accordance with the National Institutes of Health Guide for the Care and Use of Laboratory Animals and were approved by the Medical University of South Carolina Animal Care and Use Committee. Male Sprague Dawley rats $(275-300$ g) were purchased from Charles River Laboratories (Indianapolis, IN) and housed individually in a temperature- and humidity-controlled environment with a reversed light/dark cycle. Rats were maintained on $20 \mathrm{~g}$ of rat chow per day with water available ad libitum. Experiments followed 1 week of acclimation and handling. A total of 220 rats were used in this study. Thirty-one animals were eliminated from data analysis because of catheter failure or lack of discrimination between active and inactive levers, 19 animals were eliminated because of placement of cannulas or dialysis probes outside of the desired brain region, and 4 subjects were eliminated because of dialysis probe failure.

Drugs. Cocaine hydrochloride and morphine were generous gifts from the National Institute on Drug Abuse (Bethesda, MD), and D-Phe-CysTyr-D-Trp-Arg-Thr-Pen-Thr- $\mathrm{NH}_{2}$ (CTAP) was purchased from SigmaRBI (Natick, MA). Cocaine was dissolved in $0.9 \%$ sterile saline for the systemic injections and intravenous infusion. CTAP or morphine was dissolved in sterile saline for microinjection and in dialysis buffer for microdialysis.

Surgery. Surgery was performed $2 \mathrm{~d}$ after food training rats in preparation for self-administration of cocaine (see below). Subjects in the cocaine self-administration experiments were implanted with indwelling jugular catheters and guide cannula to be used for microinjections or microdialysis. Surgeries were conducted under ketamine $(87.5 \mathrm{mg} / \mathrm{kg}$ Ketaset; Fort Dodge Animal Health, Fort Dodge, IA) and xylazine (5 $\mathrm{mg} / \mathrm{kg}$ Rompum; Bayer, Shawnee Mission, KS) anesthesia. A bent-steel guide cannula (C313G; Plastics One, Roanoke, VA) was attached to SILASTIC tubing $(10 \mathrm{~cm}$; inner diameter, $0.64 \mathrm{~mm}$; outer diameter, 1.19 $\mathrm{mm}$; Dow Corning, Midland, MI) inserted into the right jugular vein $(2.7-3.0 \mathrm{~cm})$ and then was run subcutaneously and exited via a $3 \mathrm{~mm}$ biopsy hole between the shoulder blades. After surgery, the catheter was flushed daily with cefazolin antibiotic $(100 \mathrm{mg} / \mathrm{ml})$ dissolved in $0.2 \mathrm{ml}$ of heparin $(100 \mathrm{IU} / \mathrm{ml})$ to help protect against infection and catheter occlusion. Catheter patency was initially verified by infusing $0.08-0.10 \mathrm{ml}$ of methohexital sodium ( $10 \mathrm{mg} / \mathrm{ml}$, i.v.; SP Pharmaceuticals, Albuquerque, $\mathrm{NM}$ ), which produces a rapid loss of muscle tone only when administered intravenously.

All stainless-steel guide cannulas were implanted bilaterally 1 or $2 \mathrm{~mm}$ over the ventral pallidum or the nucleus accumbens [coordinates are shown as millimeters with respect to bregma (Paxinos and Watson, 1998)]; for the ventral pallidum, anteroposterior, -0.25 ; mediolateral, \pm 2.4 ; dorsoventral, -7.0 ; for the nucleus accumbens, anteroposterior, +1.2 ; mediolateral, \pm 1.6 ; dorsoventral, -6.5 ; and for the lateral hypothalamus, anteroposterior, -1.5 ; mediolateral, \pm 2.0 ; dorsoventral, -8.0 . Coordinates for microdialysis cannulas (20 gauge, $14 \mathrm{~mm}$; Plastics One) in the ventral pallidum were as follows: anteroposterior, 0.0 ; mediolateral, +3.2 ; dorsoventral, -5.2 , at $6^{\circ}$ from vertical. Guide cannulas were secured to the skull with dental cement and stainless steel screws. Obturators (Plastics One) were placed into the guide cannulas and catheter to prevent occlusion. Animals were monitored for changes in health for at least $5 \mathrm{~d}$ before beginning the experiments.

Self-administration training. To more rapidly acquire selfadministration of cocaine, all rats were given a single $15 \mathrm{~h}$ training session in an operant conditioning chamber $(30 \times 20 \times 24 \mathrm{~cm}$; Med Associates, St. Albans, VT) that was fitted with two retractable levers, a stimulus light above each lever, a food pellet dispenser between the levers, and a house light on the wall opposite to the levers. During this session, each lever press on the correct lever was reinforced by delivery of a single $45 \mathrm{mg}$ food pellet. Lever presses on the inactive lever had no programmed consequences.

Cocaine self-administration training was conducted during $2 \mathrm{~h}$ sessions during the rat's dark cycle. Rats were trained to press a lever on an fixed ratio (FR) 1 schedule of cocaine reinforcement $(0.25 \mathrm{mg} / \mathrm{kg}$ cocaine hydrochloride in $0.05 \mathrm{ml}$ over $2.7 \mathrm{~s}$; National Institute on Drug Abuse) with a $20 \mathrm{~s}$ timeout after each infusion. Correct (active) lever presses resulted in cocaine infusion and illumination of a stimulus light over the lever. The light remained on for $20 \mathrm{~s}$, during which time active lever presses were counted but resulted in no additional cocaine infusion. After the $20 \mathrm{~s}$ timeout, the light turned off. Responses on the inactive lever had no programmed consequences but were recorded. The house light was illuminated throughout each session. Data collection and cocaine delivery were controlled using Schedule Manager for Windows software version 2.09 (Med Associates). Sessions lasted for $2 \mathrm{~h}$ or until 200 reinforcements were earned. Animals remained in selfadministration training until they obtained at least 20 infusions per day on a minimum of 10 consecutive self-administration days (i.e., between 10 and $21 \mathrm{~d}$ of self-administration) and exhibited $<10 \%$ variability in active lever responding on 3 consecutive days.

Extinction and reinstatement testing. Extinction procedures commenced the day after a rat achieved the acquisition criterion (see above). The house light was illuminated throughout each session, and responses were recorded on both levers but had no programmed consequences. Rats received extinction training on a minimum of 7 consecutive days until the responding on the active lever fell to $<10 \%$ of the active lever pressing during maintenance for 3 consecutive days. The day after achieving this criterion, subjects were returned to the operant chambers for reinstatement testing.

Yoked control subjects. Some subjects served as yoked controls for the self-administering rats. In the yoked cocaine subjects, intravenous delivery of cocaine $(0.25 \mathrm{mg} / \mathrm{kg}$ over $4 \mathrm{~s})$ was paired with rats that were self-administering cocaine such that the yoked animal received the same dose and temporal pattern of cocaine delivery as the self-administering paired rat. Yoked saline rats received the mean number of intravenous infusions that all self-administering rats did on a given day. Yoked rats received the same number of training and extinction sessions as the self-administering paired rat.

Reinstatement testing, microinjection, and microdialysis procedure. In some experiments, subjects were microinjected before reinstatement testing. Obturators were removed and bilateral infusion cannulas (33 gauge) were inserted, extending $1 \mathrm{~mm}$ beyond the tip of the guide cannulas. All infusions were made in a volume of $0.3 \mu \mathrm{l}$ over $1 \mathrm{~min}$, and an additional $2 \mathrm{~min}$ was allowed for diffusion before the microinfusion cannulas were removed. Obturators were replaced, and intraperitoneal injection of cocaine $\left(5 \mathrm{or} 10 \mathrm{mg} \cdot \mathrm{ml}^{-1} \cdot \mathrm{kg}^{-1}\right.$, i.p.) or saline was administered. Animals were returned to the self-administration chambers for a $2 \mathrm{~h}$ reinstatement test. During reinstatement testing, active lever presses were counted but resulted in no reinforcement.

The dialysis probes were constructed with 1.5-2.0 mm of active dialysis membrane exposed at the tip. On the night before reinstatement testing, microdialysis probes were inserted into the ventral pallidum. Subjects were then housed in the operant chambers, in which they were given their daily ration of food and ad libitum access to water. On the following morning, dialysis buffer ( $5 \mathrm{~mm}$ glucose, $2.5 \mathrm{~mm} \mathrm{KCl,} 140 \mathrm{~mm}$ $\mathrm{NaCl}, 1.4 \mathrm{~mm} \mathrm{CaCl}$, $1.2 \mathrm{~mm} \mathrm{MgCl}$, and 0.15\% PBS, pH 7.4) was perfused through the probe $(2 \mu \mathrm{l} / \mathrm{min})$ for $2 \mathrm{~h}$, after which, $2 \mathrm{~h}$ of baseline samples were collected at $10 \mathrm{~min}$ intervals. Samples were then stored at $-80^{\circ} \mathrm{C}$ for later quantification of GABA. After the $2 \mathrm{~h}$ baseline sampling, subjects were tested for their propensity to reinstate drug-seeking behavior after a challenge injection of cocaine $\left(10 \mathrm{mg} \cdot \mathrm{ml}^{-1} \cdot \mathrm{kg}^{-1}\right.$, i.p.). Five minutes preceding systemic cocaine challenge, some subjects also received unilateral delivery of dialysis buffer or $10 \mu \mathrm{M}$ of CTAP into the ventral pallidum via reverse dialysis through the microdialysis probe. Ten minute microdialysis samples were collected across the $2 \mathrm{~h}$ subsequent to cocaine administration, and then subjects were disconnected and returned to their home cages. In a separate dialysis experiment, 


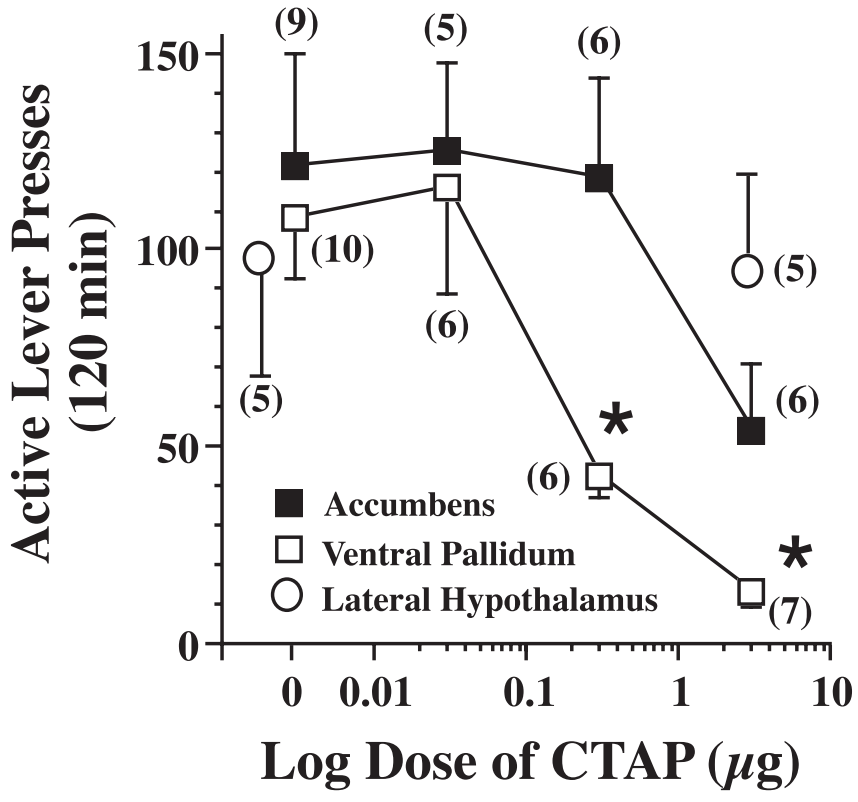

Figure 1. $\mu$ Receptors in the ventral pallidum critically regulate cocaine-induced reinstatement of drug seeking in rats extinguished from cocaine self-administration. After reaching extinction criterion (on the extinction trial the day before the reinstatement trial: ventral pallidum group, $15 \pm 3$ active lever presses; nucleus accumbens group, $9 \pm 3$ ), rats were microinjected into the ventral pallidum, nucleus accumbens, or lateral hypothalamus with CTAP or saline vehicle just before administering a cocaine-priming injection $\left(10 \mathrm{mg} \cdot \mathrm{kg}^{-1} \cdot \mathrm{ml}^{-1}\right.$, i.p.). Data were evaluated using a mixed-regression analysis, and each rat received a maximum of two reinstatement trials (ventral pallidum, $F_{(3,8)}=13.88, p=0.002$; nucleus accumbens, $\left.F_{(3,11)}=1.82, p=0.202\right)$, except the lateral hypothalamus data, which were evaluated using a paired Student's $t$ test $(p=0.687)$. All data are shown as mean \pm SEM active lever presses. The number of determinations at each dose is shown in parentheses. ${ }^{*} p<0.05$ compared with saline microinjection within each brain nucleus.

dialysis samples were collected every $20 \mathrm{~min}$, and morphine and/or CTAP $(0.1-10 \mu \mathrm{M}$, for $1 \mathrm{~h}$ each concentration) was perfused into the ventral pallidum of drug-naive rats via the reverse dialysis.

Food reinstatement. The effect of CTAP in the ventral pallidum was examined for its involvement in the ability of a food prime to elicit food-seeking behavior. Food reinstatement subjects were trained in a manner parallel to cocaine self-administering rats. They were trained to lever press on an FR-1 schedule of reinforcement (each reinforcement consisting of a single $45 \mathrm{mg}$ Noyes food pellet) in daily $2 \mathrm{~h}$ sessions. Once stable responding was achieved, the schedule of reinforcement was increased to FR-3 and then to FR-5. Subjects remained in maintenance until lever pressing stabilized $(<10 \%$ variation across 3 consecutive days). Subjects then underwent extinction training, in which lever pressing no longer resulted in food delivery. Once lever presses fell to $<10 \%$ of maintenance levels across 3 consecutive days, rats were tested for their propensity to reinstate responding for noncontingent food delivery. The session started when the levers extended into the chamber and the house light illuminated. Subjects received two pellets immediately on initiation and an additional one pellet at $2 \mathrm{~min}$ intervals for the first $20 \mathrm{~min}$ of the reinstatement session. Lever presses never resulted in food delivery. Two food reinstatement trials were conducted and were separated by additional extinction trials to ensure that rats again met the extinction criterion between test sessions. Before reinstatement sessions, the subjects received a microinjection of either saline or CTAP $(0.3-3.0 \mu \mathrm{g} /$ side in 0.3 $\mu l)$ in random order.

Photocell apparatus. To assess the general motor effects of the CTAP manipulations, locomotion was measured during a $2 \mathrm{~h}$ test session. Motor activity was monitored in clear Plexiglas chambers $(22 \times 43 \times 33 \mathrm{~cm})$ (Omnitech Electronics, Columbus, $\mathrm{OH}$ ). Each box was monitored by a series of 16 photo beams (eight on each horizontal axis) measuring horizontal activity and eight photo beams measuring vertical activity. Beam breaks were detected, counted, and recorded by IBM personal computers running Digiscan software (AccuScan Instruments, Columbus, OH). Locomotor studies commenced with a $60 \mathrm{~min}$ habituation period, and each subject was removed from its chamber, given a microinfusion of either saline or CTAP $(3.0 \mu \mathrm{g} / \mathrm{side}$ in $0.3 \mu \mathrm{l})$, followed by a systemic challenge of cocaine $\left(10 \mathrm{mg} \cdot \mathrm{kg}^{-1} \cdot \mathrm{ml}^{-1}\right.$, i.p. $)$ or saline $(1 \mathrm{ml} / \mathrm{kg}$, i.p. $)$, and then returned to the cage for $2 \mathrm{~h}$ of activity monitoring. Rats were randomly assigned to either a saline or cocaine group, and each rat was microinjected with saline and CTAP in random order, separated by a minimum 3 d intertrial interval.

Quantification of GABA. The concentration of GABA was determined using a modified "Fast Assay of GABA" obtained from the ESA (Bedford, MA). The mobile phase consisted of $15 \%$ methanol (v/v) and $100 \mathrm{~mm}$ $\mathrm{NaH}_{2} \mathrm{PO}_{4}$, pH 4.6. The GABA was separated using a reversed-phase column (HR-80; $4.6 \times 80,3 \mu \mathrm{m})$ and oxidized/reduced using coulometric detection (ESA) with precolumn derivatization of amino acids with o-phthalaldehyde. Three electrodes were used: a preinjection port guide cell $(+0.70 \mathrm{~V})$ to oxidize the mobile phase, an oxidation analytical electrode $(\mathrm{E} 1,+0.40 \mathrm{~V})$, and a reduction analytical electrode $(\mathrm{E} 2,+0.65 \mathrm{~V})$. The area under curve of the GABA peak was measured with ESA 501 Chromatography Data System and compared with an external standard curve for quantification.

Immunoblotting for $\mu$ receptors. Immunoblotting and subfraction of membrane bound receptor was conducted exactly as described previously (Toda et al., 2003). The antibody for $\mu$ receptors (Calbiochem, La Jolla, CA) was used at a 1:1000 dilution. Separate animals were used for measuring total and membrane-bound protein, and, at 2-3 weeks after cocaine self-administration or yoked saline treatments (see above), animals were decapitated, the brain was rapidly removed, and the ventral pallidum was dissected on an ice-cooled glass plate. For total protein, the tissue was immediately frozen and stored at $-80^{\circ} \mathrm{C}$ until analysis, and, for subfractionation, the tissue was immediately homogenized (Toda et al., 2003). After immunoblotting, band density was quantified using NIH Image 1.62.

Histology and statistics. After experimentation, rats were overdosed with pentobarbital ( $>100 \mathrm{mg} / \mathrm{kg}$, i.p.) and then perfused transcardially with $0.9 \%$ physiological saline, followed by $10 \%$ formaldehyde solution. Brains were dissected out and stored in 10\% formaldehyde solution until sectioning. Brains were blocked, and coronal sections $(100 \mu \mathrm{m})$ were made through the ventral pallidum, lateral hypothalamus, and nucleus accumbens with a vibratome (Technical Products International, St. Louis, MO). The sections were then stained with cresyl violet to verify anatomical placement according to the atlas of Paxinos and Watson
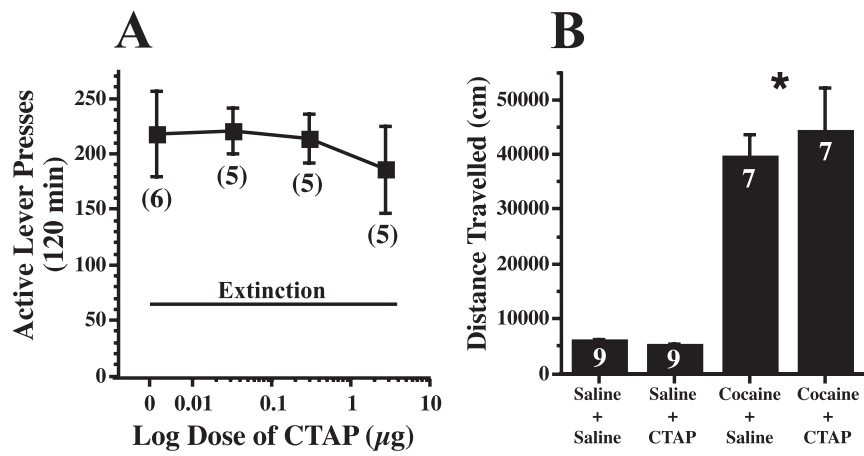

Figure 2. $\mu$ Receptor blockade in the ventral pallidum did not alter food-seeking or cocaineinduced locomotor activity. A, CTAP did not affect food seeking. Animals were trained to lever press for food (FR-5), and, after extinction to criterion, the reinstatement of lever pressing was initiated by reintroducing two food pellets. Each animal received two reinstatement trials, and the data were evaluated using a mixed-regression analysis $\left(F_{(3,12)}=0.41 ; p=0.747\right) \cdot B, \operatorname{CTAP}(10 \mu \mathrm{g})$ did not alter cocaine-induced locomotor activity. One group of rats was microinjected with CTAP (10 $\mu \mathrm{g})$ or saline into the ventral pallidum just before saline $(1 \mathrm{ml} / \mathrm{kg}$, i.p.), and another group was microinjected just before cocaine ( $15 \mathrm{mg} / \mathrm{kg}$, i.p.). Data were evaluated using a two-way ANOVA with repeated measures over microinjection, and the data are shown as mean \pm SEM distance traveled over $2 \mathrm{~h}$ after injection: systemic treatment, $F_{(1,14)}=61.99, p<0.001$; microinjection treatment, $F_{(1,14)}=1.03, p=0.331$; interaction, $F_{(1,14)}=0.21, p=0.656 .^{*} p<0.05$ compared with CTAP in $\boldsymbol{A}$, cocaine in $\boldsymbol{B}$, and systemic cocaine with saline in $\boldsymbol{B}$. 
A

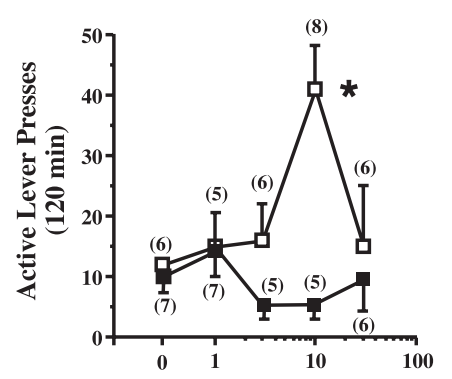

Log Dose of Morphine $(\mu \mathrm{g})$

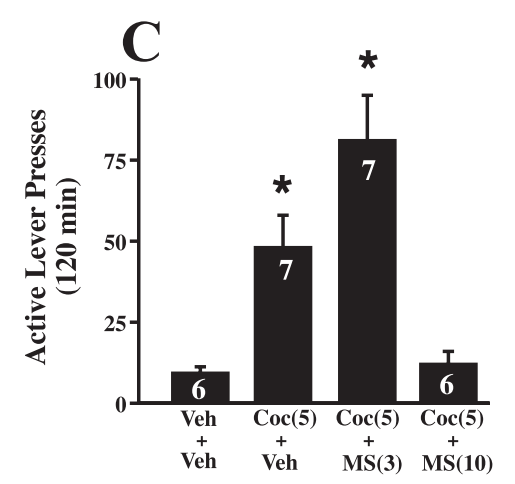

B
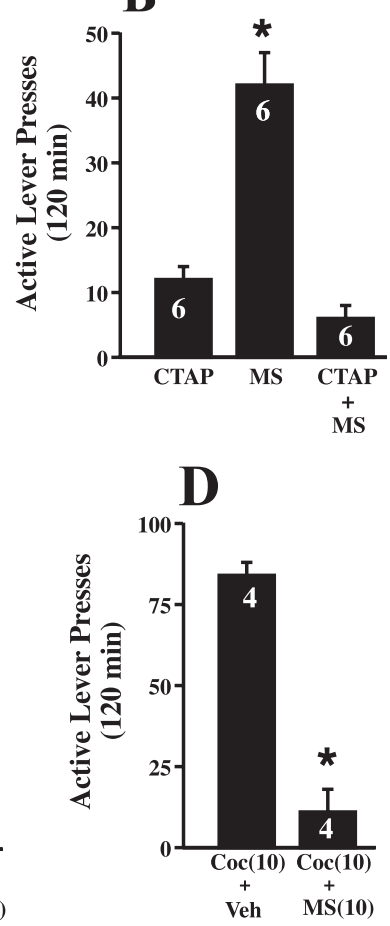

Figure 3. Stimulation of $\mu$ receptors in the ventral pallidum induces the reinstatement of cocaine seeking. $\boldsymbol{A}$, Morphine in the ventral pallidum reinstated lever pressing in cocainetrained subjects. Extinguished subjects were microinjected with saline or morphine to reinstate lever pressing. Active lever extinction baseline was as follows: ventral pallidum, $13 \pm 2$; nucleus accumbens, $9 \pm 3$. Data were evaluated using a mixed-regression analysis, and each rat had a maximum of two reinstatement trials (ventral pallidum, $F_{(4,11)}=8.45, p=0.002$; nucleus accumbens, $\left.F_{(4,11)}=1.92, p=0.181\right)$. $\boldsymbol{B}$, The reinstatement by morphine (MS; $10 \mu \mathrm{g}$ ) microinjection into the ventral pallidum was blocked by co-microinjection with CTAP ( $3 \mu \mathrm{g})$. Each animal received all three reinstatement trials in random order, and the data were evaluated using a one-way ANOVA with repeated measures over treatment: extinction baseline, $13 \pm 2$; $F_{(2,10)}=29.04 ; p<0.001$. $C$, The effect of intra-ventral pallidum morphine and systemic cocaine ( $\mathrm{Coc} ; 5 \mathrm{mg} / \mathrm{kg}$, i.p.) in reinstating drug seeking. Each animal received a maximum of two reinstatement trials, and the data were evaluated using a mixed-regression analysis: extinction baseline, $16 \pm 1 ; F_{(3,9)}=11.699 ; p=0.002$. $\boldsymbol{D}$, Intra-pallidal injection of high-dose morphine $(10 \mu \mathrm{g})$ inhibits cocaine-primed (10 mg/kg, i.p.) reinstatement. Each rat received both treatments in random order, and the data were evaluated using a paired Student's $t$ test. ${ }^{*} p<0.05$ compared with CTAP in $\boldsymbol{A}$, cocaine in $\boldsymbol{B}$, vehicle (Veh) + Veh in $\boldsymbol{C}$, and Veh + Coc in $\boldsymbol{D}$.

(1998). Subjects received two reinstatement trials, and, in experiments with more than two comparison groups, treatments were randomized and a mixed regression analysis (mixed linear model) was used (SPSS, Chicago, IL), followed by a Tukey-Kramer's multiple comparison when a significant $(p<0.05) F$ score was measured. When only two treatment groups were evaluated, a paired Student's $t$ test was used, and microdialysis data were statistically evaluated using a one-way or two-way ANOVA, followed by a least significant difference test (Milliken and Johnson, 1984).

\section{Results}

\section{$\boldsymbol{\mu}$-Opioid receptors regulate cocaine-induced reinstatement}

Rats were trained to self-administer cocaine, and the behavior was extinguished over at least $7 \mathrm{~d}$. A cocaine-priming injection (10 mg/kg, i.p.) elicited robust reinstatement of drug seeking (active lever pressing) (Fig. 1). Pretreatment of the ventral pallidum with the $\mu$ receptor antagonist CTAP produced a dosedependent reduction in cocaine-induced active lever pressing (Fig. 1). The minimum dose required to significantly reduce active lever pressing was $0.3 \mu \mathrm{g}$ of CTAP, whereas $3.0 \mu \mathrm{g}$ lowered cocaine-primed reinstatement to extinction levels of active lever

Table 1. Basal levels of extracellular GABA in the ventral pallidum corresponding to each dialysis experiment

\begin{tabular}{lcl}
\hline Treatment group & $n$ & $\begin{array}{l}\text { GABA } \\
\text { (pmol/sample) }\end{array}$ \\
\hline CTAP & 7 & $6.8 \pm 1.4$ \\
Morphine & 7 & $5.0 \pm 1.4$ \\
CTAP plus morphine & 6 & $4.2 \pm 0.7$ \\
Yoked saline & 8 & $6.0 \pm 0.9$ \\
Yoked cocaine & 6 & $7.3 \pm 1.5$ \\
Self-administered cocaine & 11 & $5.5 \pm 1.6$ \\
$\quad$ Cocaine, reinstate & 5 & $3.9 \pm 0.8$ \\
$\quad$ Cocaine, no reinstate & 6 & $6.6 \pm 1.6$ \\
Yoked saline plus morphine & 6 & $5.5 \pm 0.5$ \\
Yoked cocaine plus morphine & 6 & $6.2 \pm 0.8$ \\
Self-administered plus morphine & 6 & $6.4 \pm 0.5$ \\
\hline
\end{tabular}

pressing (active lever pressing during extinction for the data in Fig. $1 A$ was $15 \pm 3$ ). The nucleus accumbens is adjacent and rostral to the ventral pallidum, contains enkephalinergic afferents and $\mu$ receptors (Svingos et al., 1996), and is experimentally characterized as a brain region critical to the rewarding and reinstating properties of many drugs of abuse (Di Chiara, 2002; Everitt and Wolf, 2002). Although the highest dose of CTAP $(3 \mu \mathrm{g})$ in the accumbens appeared to reduce cocaine-induced lever pressing, the effect was not statistically significant (Fig. 1). Finally, microinjection of the highest dose of CTAP $(3 \mu \mathrm{g})$ made caudal to the ventral pallidum in the lateral hypothalamus did not reduce cocaine-induced reinstatement (Fig. 1). At no dose of CTAP or in any brain site did inactive lever pressing increase significantly over levels observed during the last day of extinction.

Two experiments were conducted to identify effects of CTAP that could nonspecifically interfere with cocaine-induced lever pressing. In the first experiment, animals were extinguished from food self-administration (FR-5 training schedule), and it was found that, over the dosage range producing effects on cocaine reinstatement, CTAP had no effect on food-primed reinstatement of active lever pressing (Fig. 2 A). At no dose of CTAP did inactive lever pressing increase significantly over levels observed during the last day of extinction. Akin to a previous report with intra-ventral pallidum injection of $\mu$ antagonists (Skoubis and Maidment, 2003), a dose of CTAP (3 $\mu \mathrm{g}$ ) producing maximum inhibition of cocaine-primed reinstatement did not reduce cocaine-induced locomotor activity (Fig. 2 B). Similarly, the motor response to an injection of saline was not affected by pretreatment with CTAP (Fig. $2 B$ ).

In a converse experiment with the $\mu$-opioid agonist morphine, it was shown that stimulating $\mu$ receptors in the ventral pallidum elicited reinstatement of drug seeking in rats extinguished from cocaine self-administration (Fig. 3A). The effect of morphine was biphasic, showing a peak effect at $10 \mu \mathrm{g}$ and no effect when a higher dose $(30 \mu \mathrm{g})$ was used. No dose of morphine significantly increased inactive lever pressing over extinction baseline. Akin to the differential effects of CTAP in the ventral pallidum and nucleus accumbens, microinjection of morphine into the accumbens did not reinstate lever pressing over the examined dose range (1-30 $\mu \mathrm{g}$ ) (Fig. 3A). Verifying involvement of $\mu$-opioid receptors, the reinstatement of lever pressing by morphine $(10 \mu \mathrm{g})$ in the ventral pallidum was abolished by coadministration with CTAP $(1 \mu \mathrm{g})$ (Fig. $3 B$ ). The possibility that systemic cocaine administration and intra-ventral pallidum morphine both induce reinstatement via a shared mechanism was supported by showing that increased lever pressing elicited 
by an approximate $\mathrm{ED}_{50}$ dose of cocaine [ 5 $\mathrm{mg} / \mathrm{kg}$, i.p. (Cornish and Kalivas, 2000; Bowers et al., 2004)] was augmented by subthreshold dose of intra-ventral pallidum morphine (3 $\mu \mathrm{g}$ ) (Fig. 3C). Moreover, cocaine appeared to increase the potency of morphine in the ventral pallidum. Thus, 10 $\mu \mathrm{g}$ of morphine alone produced a maximum effect in the biphasic dose-response curve (Fig. $3 A$ ), but, when coadministered with cocaine, this dose of morphine prevented cocaine-induced reinstatement akin to $30 \mu \mathrm{g}$ of morphine administered alone into the ventral pallidum. To further evaluate the inhibitory effect of morphine on cocaine-induced reinstatement, $30 \mu \mathrm{g}$ of morphine was also shown to also prevent reinstatement induced by a higher dose of cocaine (10 mg/kg, i.p.) (Fig. 3D).

\section{Regulation of GABA release by $\mu$ receptors modulates cocaine-induced reinstatement}

In vivo microdialysis in the ventral pallidum was used to evaluate the role of GABA in the ability of $\mu$ receptors to regulate the reinstatement of cocaine seeking. Basal levels of GABA for all treatment groups are shown in Table 1. In the first experiment, it was shown in drug-naive rats that stimulating $\mu$ receptors in the ventral pallidum by reverse dialysis of morphine reduced the concentration of extracellular GABA, with a threshold effect at $1.0 \mu \mathrm{M}$ morphine (Fig. $4 A$ ). The reduction in GABA produced by 1.0 or $10 \mu \mathrm{M}$ morphine was abolished by coperfusion with CTAP $(10 \mu \mathrm{M})$ (Fig. $4 A$ ), and a range of CTAP concentrations $(0.1-10 \mu \mathrm{M})$ perfused without morphine did not alter extracellular GABA levels (Fig. 4A).

Because blocking $\mu$ receptors in the ventral pallidum prevented reinstatement (Fig. 1), the dialysis data in Figure $4 A$ posed the possibility that cocaine-induced reinstatement resulted from $\mu$ receptor-mediated reduction in extracellular GABA. Rats were extinguished from cocaine selfadministration, and microdialysis in the ventral pallidum was conducted during a cocaine-primed reinstatement trial. A significant reduction in extracellular GABA levels was measured between 10 and $40 \mathrm{~min}$ after cocaine administration (Fig. $4 B$ ). Supporting involvement of endogenous $\mu$ receptor stimulation, the reduction in extracellular GABA was abolished by perfusing the ventral pallidum with CTAP $(10 \mu \mathrm{M})$ beginning $5 \mathrm{~min}$ before injecting cocaine. To determine whether the reduction in GABA required animals to have self-administered cocaine or was a pharmacological consequence of withdrawal from repeated cocaine administration, the cocaineinduced reduction in extracellular GABA in rats trained previously to self-administer cocaine was compared with yoked saline- and yoked cocaine-treated subjects. Cocaine produced a significantly smaller decrease in extracellular GABA in the yoked-saline subjects compared with either chronic cocaine group, and the yoked cocaine group demonstrated a reduction equivalent to the rats trained to self-administer cocaine (Fig. 4C).
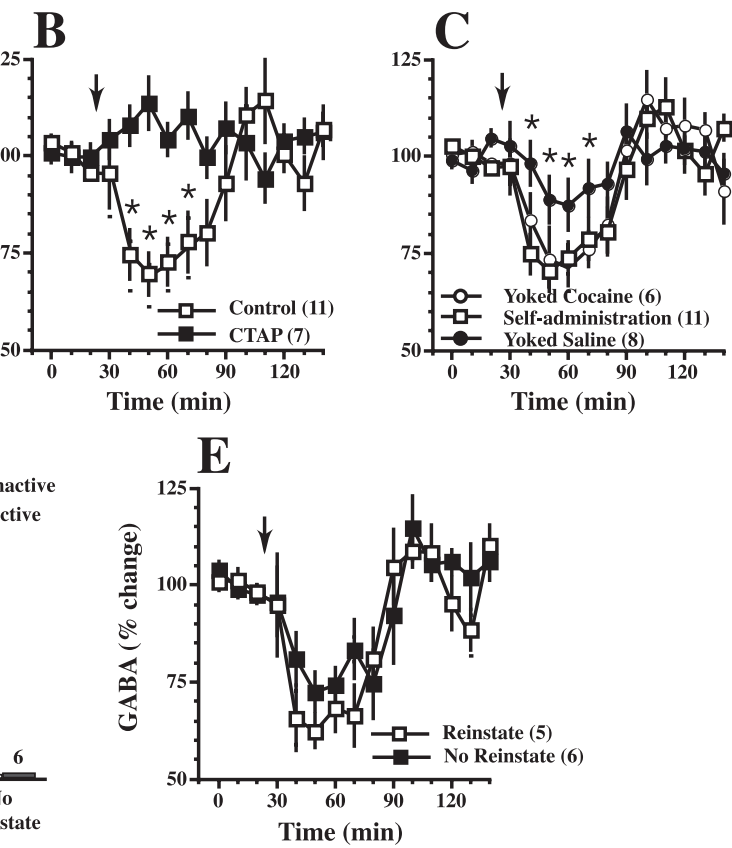

Figure 4. Cocaine reduces extracellular GABA in the ventral pallidum. $\boldsymbol{A}$, In drug-naive rats, the reverse dialysis of morphine (MS) through a probe in the ventral pallidum reduced extracellular GABA, an effect blocked by coperfusion with CTAP. Increasing doses of morphine or CTAP were added separately to the dialysis buffer at $60 \mathrm{~min}$ intervals (doses are shown above arrows as determinations is shown in parentheses, and the data were evaluated using a two-way repeated-measures ANOVA over time: (20.86, $p<0.001$; time, $F_{(11,187)}=9.06, p<0.001$; interaction, $F_{(22,187)}=3.48, p<0.001$. B, A cocaine all treatment groups ( 50 and 60 min in yoked saline; $40-80 \mathrm{~min}$ in both cocaine groups), but the reduction was larger in the

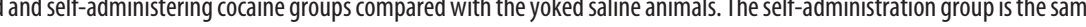
$F_{(2,22)}=2.09, p=0.147$; time, $F_{(14,308)}=14.41, p<0.001$; interaction, $F_{(28,308)}=2.03, p=0.002$. D, Not all animals pallidum. Active and inactive lever presses are shown for all animals and then divided between animals showing $>20$ active lever presses and those showing $<20$. Active and inactive lever presses were compared using a paired Student's $t$ test. $\boldsymbol{E}$, If the dialysis animals showing reinstatement demonstrated statistically equivalent reductions in extracellular GABA in response to an injection of cocaine. ${ }^{*} p<0.05$ compared with basal glutamate values in $\boldsymbol{A}$, between control and CTAP in $\boldsymbol{B}$, with yoked saline in $\boldsymbol{C}$, and between active and inactive in $\boldsymbol{D}$.

Behavioral data were obtained simultaneous with dialysis measures of extracellular GABA, and 6 of the 11 animals trained to self-administer cocaine did not show reinstatement of lever pressing in response to the cocaine-priming injection ( $<20$ active lever presses over $2 \mathrm{~h}$ after cocaine injection) (Fig. $4 \mathrm{D}$ ). This rate of reinstatement is low relative to other studies from our laboratory in which $>90 \%$ of rats reinstate to a cocaine-priming injection (Cornish and Kalivas, 2000; McFarland and Kalivas, 2001; Bowers et al., 2004; McFarland et al., 2004) and may result at least in part from the presence of a dialysis probe in the ventral pallidum inhibiting behavioral responding. When the dialysis data were divided according to rats that reinstated versus those that did not, the reduction in GABA was equivalent regardless of whether or not the animals reinstated lever pressing (Fig. 4E).

Potential adaptations in $\mu$ receptors in the ventral pallidum by withdrawal from repeated cocaine

To determine possible mechanisms whereby withdrawal from cocaine treatment is augmenting cocaine-induced reduction of extracellular GABA, morphine was administered in increasing con- 


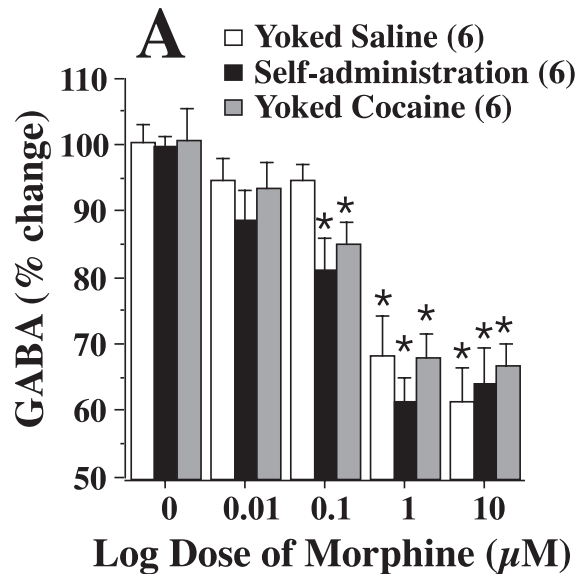

Figure 5. Increased sensitivity to $\mu$ receptor stimulation contributed to the augmented decrease in GABA produced by withdrawal from cocaine. $A$, Lower doses of morphine reduced GABA in the ventral pallidum of rats trained to self-administer or yoked to cocaine relative to yoked saline subjects. Experiment was conducted as in Figure $3 A$, and the data are shown as the mean $\pm S E M$ of the average of the last two samples obtained at each dose of morphine ( 0 is baseline). Data were evaluated using a two-way ANOVA with repeated measures over dose, followed by a one-way ANOVA with repeated measures over time within each treatment group: treatment, $F_{(2,15)}=1.44, p=0.267$; time, $F_{(14,210)}=35.42, p<0.001$; interaction, $F_{(28,210)}=1.11, p=0.327$. $\boldsymbol{B}$, Representative Western blots showing the lack of effect of cocaine self-administration on total and membrane-bound $\mu$-opioid receptor levels in the ventral pallidum. ${ }^{*} p<0.05$ comparing all doses of morphine with baseline $(0)$ within each treatment group. C, Cocaine; Sa, saline.

centrations through a microdialysis probe in the ventral pallidum. Figure $5 A$ shows that the threshold dose for morphine to elicit a significant reduction in extracellular GABA was lower in both cocaine self-administering and yoked cocaine groups compared with the yoked saline group. Thus, whereas a dose of $0.1 \mu \mathrm{M}$ morphine significantly reduced GABA in the cocaine groups, $1.0 \mu \mathrm{M}$ was necessary in the yoked saline animals. Figure $5 B$ shows representative immunoblots for $\mu$ receptors in the ventral pallidum and reveals no significant difference in either total (saline, $100 \pm 8 \%, n=8$; cocaine, $103 \pm 12 \%, n=8$ ) or membrane-bound protein (saline, $100 \pm 15 \%, n=7$; cocaine, $112 \pm 22 \%, n=7$ ), indicating that the increased response to morphine was not the result of increased $\mu$ receptor content or membrane distribution.

\section{Histology}

Figure 6 illustrates histological localization of dialysis probe active membranes and the tips of microinjection cannulas in the ventral pallidum, lateral hypothalamus, and nucleus accumbens. In the nucleus accumbens, the microinjection cannulas were located in the core subcompartment (Fig. 6A). The majority of the dialysis probes and microinjection cannula tips were located in the rostral and subcommissural ventral pallidum (Fig. 6B,C). Cannula tips in the lateral hypothalamus were located medial to the substantia innominata and lateral to the anterior hypothalamus and caudal aspect of the bed nucleus of the stria terminalis (Fig. 6B).

\section{Discussion}

The present data demonstrate that $\mu$ receptor stimulation in the ventral pallidum is required for rats to reinstate drug seeking in response to a cocaine-priming injection. The reliance on $\mu$ receptor stimulation was associated with an augmented capacity of $\mu$ receptor stimulation to reduce extracellular GABA levels in the ventral pallidum. Thus, whereas cocaine administration in yoked saline control subjects reduced extracellular GABA in the ventral pallidum, after withdrawal from repeated cocaine, the reduction produced by an acute cocaine injection was significantly enhanced. Akin to the reinstatement of drug seeking, the reduction in GABA was abolished by blocking $\mu$ receptors with CTAP. Given that enkephalin is heavily colocalized with GABA in the projection from the accumbens to ventral pallidum (Zahm et al., 1985), it is
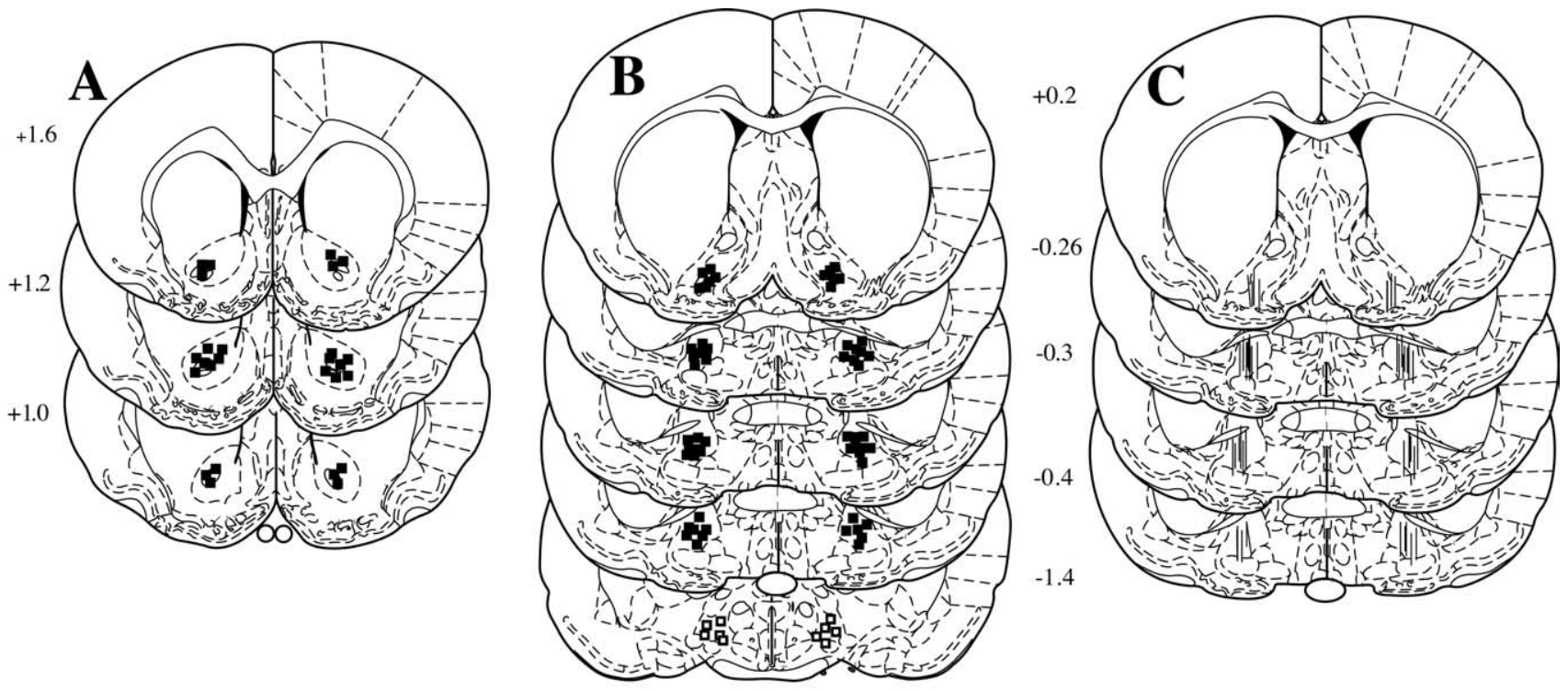

Figure 6. Histological localization of microdialysis and microinjection cannulas in the ventral pallidum and nucleus accumbens. $A$, Microinjection cannula tips in the core of the nucleus accumbens (Paxinos and Watson, 1998). B, Microinjection cannula tips in the ventral pallidum (filled squares) were localized primarily to the rostral subcommissural portion. The cannula tips in the lateral hypothalamus (open squares) were located medial to the substantia innominata. C, Location of the $1.5 \mathrm{~mm}$ of active membrane from dialysis probes inserted into the ventral pallidum. 
possible that chronic cocaine enhances the ability of an acute cocaine injection to release enkephalin and/or promote enkephalin signaling through $\mu$ receptors. However, it is important to note that a similar augmented reduction in GABA occurred in both yoked cocaine subjects and rats trained to self-administer cocaine. Thus, the augmented $\mu$ receptor regulation of extracellular GABA in the ventral pallidum is a pharmacologically induced neuroadaptation that occurs regardless of the behavioral contingencies associated with repeated cocaine administration and withdrawal. Combined with the observation that reinstatement is prevented by $\mu$ receptor blockade in the ventral pallidum, these data indicate that, although a cocaine-induced, $\mu$-dependent reduction in extracellular GABA may be necessary for reinstatement to occur, it is not a sufficient condition.

\section{Reinstatement circuitry and GABA in the ventral pallidum}

By differentially inactivating specific nuclei in corticolimbicstriatal circuitry, it was shown previously that both stress- and cocaine-induced reinstatement of cocaine seeking depend on the core of the nucleus accumbens and the ventral pallidum (McFarland and Kalivas, 2001; McFarland et al., 2004). Moreover, unilateral inactivation experiments reveal a series circuit connecting the prefrontal cortex, accumbens core, and ventral pallidum that may be a "final common pathway" for reinstatement induced by either stress or cocaine (Kalivas and Volkow, 2005). Although a number of neurochemical and pharmacological studies have demonstrated the critical involvement of enhanced glutamate release in the projection from the prefrontal cortex to the accumbens (Cornish and Kalivas, 2000; Di Ciano and Everitt, 2001; McFarland et al., 2003), this is the first study beyond the inactivation studies to evaluate the projection from the accumbens to the ventral pallidum in the reinstatement of cocaine seeking.

The present data indicate that a $\mu$ receptor-dependent reduction in GABA transmission in the ventral pallidum may be a necessary condition for reinstatement to occur. This is consistent with the fact that the previous inactivation studies often used GABA agonists to inhibit reinstatement (McFarland and Kalivas, 2001; McFarland et al., 2004), thereby indicating that restoring GABA tone in the ventral pallidum prevents reinstatement. Although the present experiments show that a reduction in GABA occurs in parallel with the reinstatement of drug seeking, the fact that augmented reductions occurred in rats trained to selfadminister cocaine as well as yoked cocaine animals argues that the reduction does not drive the reinstatement response. Rather, the augmented reduction in GABA after withdrawal from repeated cocaine may nonspecifically promote behavioral responding. Supporting a more general role for GABA transmission in the ventral pallidum in behavioral activation, intra-ventral pallidum administration of GABA antagonists promotes spontaneous locomotor activity and feeding in satiated rats (Austin and Kalivas, 1990; Stratford et al., 1999), and GABA agonists reduce novelty and psychostimulant-induced motor activity, as well as startle responses (Mogenson and Nielsen, 1983; Swerdlow et al., 1990; Hooks and Kalivas, 1995; McFarland and Kalivas, 2001). Indeed, the reduction in extracellular GABA in response to a cocaine challenge may be more a reflection of behavioral sensitization than reinstatement of drug seeking. For example, similar to reduced GABA levels, the sensitization of reward or locomotor behavior is produced by either contingent or noncontingent administration of repeated cocaine (Hooks et al., 1994; Vezina et al., 1999). Although the augmented reduction in GABA by cocaine may reflect behavioral sensitization and not specifically encode drug seeking, it nonetheless appears to be required for drug seek- ing to occur because blocking $\mu$ receptors in the ventral pallidum prevented both the cocaine-induced reduction in extracellular GABA and the reinstatement of cocaine seeking.

Mechanisms for $\boldsymbol{\mu}$ receptor regulation of GABA transmission $\mu$ receptors are located, in part, presynaptically on axon terminals in the accumbens-ventral pallidum projection (Olive et al., 1997), and stimulating $\mu$ receptors lowers evoked and basal extracellular GABA levels in the pallidal complex (Kalivas et al., 2001; Schroeder and Schneider, 2002). Moreover, extracellular recordings from the ventral pallidum reveal a role for presynaptic $\mu$ receptors in regulating the excitability of pallidal neurons. Thus, the inhibition of neuronal activity in the ventral pallidum elicited by stimulating the nucleus accumbens is reduced after iontophoretic delivery of $\mu$ receptor agonist (Napier and Mitrovic, 1999). Correspondingly, presynaptic $\mu$ receptors mediate the reduction in extracellular GABA because pretreatment with CTAP prevented this effect of cocaine. Interestingly, Napier and Mitrovic (1999) also noted that, when ejection currents were increased, $\mu$ agonists directly inhibited ventral pallidal neurons by stimulating postsynaptic $\mu$ receptors. The differential sensitivity of presynaptic versus postsynaptic $\mu$ receptors may have contributed to the biphasic dose-response curve for morphineinduced reinstatement. Thus, the dose of morphine-inducing reinstatement may have produced a predominately presynaptic effect on GABAergic afferents from the accumbens to disinhibit ventral pallidal neurons, whereas higher doses may have directly inhibited pallidal neurons. The fact that $\mu$ receptor stimulation in the ventral pallidum was additive with cocaine-induced reinstatement is consistent with the possibility that systemic cocaine is releasing enkephalin from accumbens afferents. Moreover, the inhibition of cocaine by higher doses of morphine may result from direct inhibition of pallidal neurons by morphine, thereby countering the presynaptic disinhibitory effect of $\mu$ receptor stimulation on GABA release. Finally, it is important to note that, although the data are consistent with dose-dependent activation of presynaptic $\mu$ receptors to inhibit GABA release, the methods used in this report cannot prove a presynaptic site of action, and it is possible that $\mu$ receptors located postsynaptically on pallidal cells may also regulate extracellular GABA levels.

Regardless of the cellular location of $\mu$ receptors involved in regulating extracellular GABA in the ventral pallidum, the fact that CTAP abolished the decrease in GABA elicited by cocaine demonstrates that the reduction is mediated by the release of endogenous opioids and subsequent stimulation of $\mu$ receptors. Thus, the sensitization of reduction by cocaine in GABA may result from enhanced release of enkephalin and/or augmented signaling through $\mu$ receptors. Some studies indicate that increased enkephalin transmission may result from repeated exposure to cocaine or heroin. Thus, repeated administration of heroin increases extracellular enkephalin (Olive and Maidment, 1998) and reduces extracellular GABA (Caille and Parsons, 2004) in the ventral pallidum. Moreover, withdrawal from both contingent or noncontingent cocaine administration increases the concentration of the enkephalin precursor preproenkephalin throughout the accumbens (Crespo et al., 2001), and the majority of preproenkephalin-expressing neurons in the accumbens project to the ventral pallidum (Lu et al., 1998).

Although the present study did not evaluate enkephalin release, some evidence was obtained indicating increased responsiveness to $\mu$ receptor stimulation. Thus, the ability of morphine to reduce extracellular GABA in the ventral pallidum was augmented by withdrawal from repeated cocaine; however, this ef- 
fect was not related to increased $\mu$ receptor concentration or insertion of receptor into the membrane. In support of a role for enhanced $\mu$ receptor signaling, after the administration of repeated cocaine, an increase in $\mu$ receptor-induced $\left[{ }^{35} \mathrm{~S}\right] \mathrm{GTP} \gamma \mathrm{S}$ binding was measured in many cortical and subcortical forebrain regions (Schroeder et al., 2003). Although the Schroeder et al. study did not specifically quantify $\mu$ receptor-regulated $\left[{ }^{35} \mathrm{~S}\right] \mathrm{GTP} \gamma \mathrm{S}$ binding in the ventral pallidum, augmentation by repeated cocaine was observed in all areas quantified in the adjacent nucleus accumbens. Thus, although additional work is necessary, some evidence exists arguing that neuroadaptations in both presynaptic enkephalin release and postsynaptic $\mu$ receptor signaling could contribute to the augmented decrease in extracellular GABA that is associated with the reinstatement of cocaine seeking.

\section{Relevance to addiction}

The reinstatement of drug seeking is proposed to model relapse in addicts (Shalev et al., 2002), and the present data indicate that endogenous enkephalin transmission in the ventral pallidum is a critical mediator of cocaine reinstatement. This is consistent with literature showing that the GABA/enkephalin projection from the nucleus accumbens to the ventral pallidum regulates cocaineand stress-induced drug seeking (Kalivas and Volkow, 2005). Recently, it was shown that administration of the nonselective $\mu$ antagonist naltrexone may be effective in reducing relapse in alcoholics (O’Brien, 2003; Myrick and Anton, 2004). Moreover, the fact that inhibition of extracellular GABA may mediate the ability of $\mu$ receptors to regulate reinstatement could account for the preliminary data that GABA agonists can inhibit relapse in drug addicts (Addolorato et al., 2002; Assadi et al., 2003; Rubio et al., 2004). Given the present findings, it is reasonable to propose that the apparent efficacy of naltrexone and GABA agonists in treating addiction may result in part from a shared mechanism in the ventral pallidum.

\section{References}

Addolorato G, Caputo F, Capristo E, Domenicali M, Bernardi M, Janiri L, Agabio R, Colombo G, Gessa GL, Gasbarrini G (2002) Baclofen efficacy in reducing alcohol craving and intake: a preliminary double-blind randomized controlled study. Alcohol Alcohol 37:504-508.

Assadi SM, Radgoodarzi R, Ahmadi-Abhari SA (2003) Baclofen for maintenance treatment of opioid dependence: a randomized double-blind placebo-controlled clinical trial [ISRCTN32121581]. BMC Psychiatry 3:16.

Austin MC, Kalivas PW (1990) Enkephalinergic and GABAergic modulation of motor activity in the ventral pallidum. J Pharmacol Exp Ther 252:1370-1377.

Bourdelais A, Kalivas PW (1990) Amphetamine lowers extracellular GABA concentration in the ventral pallidum. Brain Res 516:132-136.

Bowers MS, McFarland K, Lake RW, Peterson YK, Lapish CC, Gregory ML, Lanier SM, Kalivas PW (2004) Activator of G-protein signaling 3: a gatekeeper of cocaine sensitization and drug-seeking. Neuron 42:269-281.

Caille S, Parsons LH (2004) Intravenous heroin self-administration decreases GABA efflux in the ventral pallidum: an in vivo microdialysis study in rats. Eur J Neurosci 20:593-596.

Cornish J, Kalivas P (2000) Glutamate transmission in the nucleus accumbens mediates relapse in cocaine addiction. J Neurosci 20:RC89(1-5).

Crespo JA, Manzanares J, Oliva JM, Corchero J, Palomo T, Ambrosio E (2001) Extinction of cocaine self-administration produces a differential time-related regulation of proenkephalin gene expression in rat brain. Neuropsychopharmacology 25:185-194.

Di Chiara G (2002) Nucleus accumbens shell and core dopamine: differential role in behavior and addiction. Behav Brain Res 137:75-114.

Di Ciano P, Everitt BJ (2001) Dissociable effects of antagonism of NMDA and AMPA/KA receptors in the nucleus accumbens core and shell on cocaine-seeking behavior. Neuropsychopharmacology 25:341-360.
Di Ciano P, Everitt BJ (2004) Direct interactions between the basolateral amygdala and nucleus accumbens core underlie cocaine-seeking behavior by rats. J Neurosci 24:7167-7173.

Everitt BJ, Wolf ME (2002) Psychomotor stimulant addiction: a neural systems perspective. J Neurosci 22:3312-3320.

Goldstein RA, Volkow ND (2002) Drug addiction and its underlying neurobiological basis: neuroimaging evidence for the involvement of the frontal cortex. Am J Psychiatry 159:1642-1652.

Gong W, Neill D, Justice Jr JB (1996) Conditioned place preference and locomotor activation produced by injection of psychostimulants into ventral pallidum. Brain Res 707:64-74.

Hooks MS, Kalivas PW (1995) The role of mesoaccumbens-pallidal circuitry in novelty-induced behavioral activation. Neuroscience 64:587-598.

Hooks MS, Duffy P, Striplin C, Kalivas PW (1994) Behavioral and neurochemical sensitization following cocaine self-administration. Psychopharmacology 115:265-272.

Hubner CB, Koob GF (1990) The ventral pallidum plays a role in mediating cocaine and heroin self-administration in the rat. Brain Res 508:20-26.

Johnson PI, Stellar JR, Paul AD (1993) Regional reward differences within the ventral pallidum are revealed by microinjections of a mu opiate receptor agonist. Neuropharmacology 32:1305-1314.

Kalivas P, Jackson D, Romanidies A, Wyndham L, Duffy P (2001) Involvement of pallidothalamic circuitry in working memory. Neuroscience 104:129-136.

Kalivas PW, Volkow ND (2005) The neurobiology of addiction: a pathology of motivation and choice. Am J Psychiatry, in press.

Lu X-Y, Ghasemzadeh MB, Kalivas PW (1998) Expression of D1 receptor, $D 2$ receptor, substance $P$ and enkephalin messenger RNAs in the neurons projecting from the nucleus accumbens. Neuroscience 82:767-780.

McBride WJ, Murphy JM, Ikemoto S (1999) Localization of brain reinforcement mechanisms: intracranial self-administration and intracranial place-conditioning studies. Behav Brain Res 101:129-152.

McFarland K, Kalivas PW (2001) The circuitry mediating cocaine-induced reinstatement of drug-seeking behavior. J Neurosci 21:8655-8663.

McFarland K, Lapish CC, Kalivas PW (2003) Prefrontal glutamate release into the core of the nucleus accumbens mediates cocaine-induced reinstatement of drug-seeking behavior. J Neurosci 23:3531-3537.

McFarland K, Davidge SB, Lapish CC, Kalivas PW (2004) Limbic and motor circuitry underlying footshock-induced reinstatement of cocaine-seeking behavior. J Neurosci 24:1551-1560.

Milliken GA, Johnson DE (1984) Analysis of messy data, Vol I, Designed experiments. Belmont, CA: Lifetime Learning Publications.

Mogenson GJ, Nielsen MA (1983) Evidence that an accumbens to subpallidal GABAergic projection contributes to locomotor activity. Brain Res Bull 11:309-314.

Myrick H, Anton R (2004) Recent advances in the pharmacotherapy of alcoholism. Curr Psychiatry Rep 6:332-338.

Napier T, Mitrovic I (1999) Opioid modulation of ventral pallidal inputs. Ann NY Acad Sci 877:176-201.

O'Brien CP (2003) Research advances in the understanding and treatment of addiction. Am J Addict 12 [Suppl 2]:S36-S47.

Olive MF, Maidment NT (1998) Repeated heroin administration increases extracellular opioid peptide-like immunoreactivity in the globus pallidus/ventral pallidum of freely moving rats. Psychopharmacology 139:251-254.

Olive MF, Anton B, Micevych P, Evans CJ, Maidment NT (1997) Presynaptic versus postsynaptic localization of $\mu$ - and $\delta$-opioid receptors in dorsal and ventral striatalpallidal pathways. J Neurosci 17:7471-7479.

Paxinos G, Watson C (1998) The rat brain in stereotaxic coordinates, Ed 4. New York: Academic.

Rubio G, Ponce G, Jimenez-Arriero MA, Palomo T, Manzanares J, Ferre F (2004) Effects of topiramate in the treatment of alcohol dependence. Pharmacopsychiatry 37:37-40.

Schroeder JA, Schneider JS (2002) GABA-opioid interactions in the globus pallidus: [D-Ala2]-Met-enkephalinamide attenuates potassium-evoked GABA release after nigrostriatal lesion. J Neurochem 82:666-673.

Schroeder JA, Niculescu M, Unterwald EM (2003) Cocaine alters mu but not delta or kappa opioid receptor-stimulated in situ [35S]GTPgammaS binding in rat brain. Synapse 47:26-32.

Shalev U, Grimm JW, Shaham Y (2002) Neurobiology of relapse to heroin and cocaine seeking: a review. Pharmacol Rev 54:1-42. 
Skoubis PD, Maidment NT (2003) Blockade of ventral pallidal opioid receptors induces a conditioned place aversion and attenuates acquisition of cocaine place preference in the rat. Neuroscience 119:241-249.

Stratford TR, Kelley AE, Simansky KJ (1999) Blockade of GABAA receptors in the medial ventral pallidum elicits feeding in satiated rats. Brain Res 825:199-203.

Svingos AL, Moriwaki A, Wang JB, Uhl GR, Pickel VM (1996) Ultrastructural immunocytochemical localization of $\mu$-opioid receptors in rat nucleus accumbens: extrasynaptic plasmalemmal distribution and association with leu ${ }^{5}$-enkephalin. J Neurosci 16:4162-4171.

Swerdlow NR, Braff DL, Geyer MA (1990) GABAergic projection from nucleus accumbens to ventral pallidum mediates dopamine-induced sensorimotor gating deficits of acoustic startle in rats. Brain Res 532:146-150.
Toda S, Alguacil LF, Kalivas PW (2003) Repeated cocaine administration changes the function and subcellular distribution of adenosine A1 receptor in the rat nucleus accumbens. J Neurochem 87:1478-1484.

Vezina P, Pierre PJ, Lorrain DS (1999) The effect of previous exposure to amphetamine on drug-induced locomotion and self-administration of a low dose of the drug. Psychopharmacology 147:125-134.

Waldhoer M, Bartlett SE, Whistler JL (2004) Opioid receptors. Annu Rev Biochem 73:953-990.

Xi Z, Stein E (2000) Increased mesolimbic GABA concentration blocks heroin self-administration in the rat. J Pharmacol Exp Ther 294:613-619.

Zahm DS, Zaborszky L, Alones VE, Heimer L (1985) Evidence for the coexistence of glutamate decarboxylase and met-enkephalin immunoreactivities in axon terminals of rat ventral pallidum. Brain Res 325:33-50. 